\title{
Nurturing the Growth of Writing in the Kindergarten and Grade One Years: How are the ESL Children Doing?
}

\author{
Mayling Chow
}

Children want to write. This desire to write has always been underestimated by the adults around them. Their early attempts to communicate in writing are viewed with amusement or ignored. Adults have underestimated children's urges to make marks on paper because of a lack of understanding of the writing process (Graves 1982). In recent years, however, young children's experimentation with writing has been seriously observed and studied in an effort to better understand the role of writing in language acquisition. Studies on the development of writing in pre-schoolers (Clay 1975, Ferreiro \& Teberosky 1982), of one child's natural growth in language - spoken and written - within a supportive and responsive environment (Bissex 1980), and on the writing processes of young children (Graves 1980) have documented the similarities between oral language development and the later acquisition of written language. These studies focussed attention on the cognitive and social processes involved in learning to write. More importantly, these studies and others have served to point out how schools have not "connected" children's natural acquisition of literacy with formal literacy instruction (Dyson 1982).

Young children from a literate society are constantly exposed to the symbols and products of their print-oriented surrounding. Street signs, store fronts, commercial food labels and fast-food restaurants are all part of these young children's environment. Billboards, newspapers, books, television also play an important part in a literate society. It is not surprising, then, that long before children enter school, they have begun to discover how print is organized and how it is used by the members of their society. These children try to make sense of the literate forms in their environment in much the same way they try to make sense of the rest of their environment. In responding to, interacting with, and organizing the written language in their daily world, they begin to understand: 1) the significance of written language; 2) the oral labels used when referring to written language; 3 ) the purposes written language serve for different 
people; and 4) the variety of forms used to construct meanings communicated by written language (Goodman 1980). It is in these interactions between the learner and his world that the origins of the literacy can be found.

Researchers in oral language development provided insight into the large amount of language learning which goes on in young children from birth to school entrance. Children learn to speak and listen and develop the rules for oral language without the benefit of formal instruction (Brown 1973). Language development is an active, not a passive process. From birth, the children are engaged in a developmental learning task as they test hypotheses about the structure and use of language. Menyuk (1971) suggested that what may appear to be errors (that is differences between the adult's speech and child's speech) are in fact, stages in the child's development of knowledge of the language. Unconventional patterns in writing and misspellings, too, can be viewed as stages in a child's development of language as he strives to approximate adult writing (Chomsky 1979, Graves 1980, Hendersen \& Beers 1980, Bissex 1981, Clay 1975, Gentry 1982).

Language development, whether written or oral, follows natural learning processes. Children learn to talk by interacting with an environment that provides rich information about language. They learn to speak by speaking. Children also grow as writers by interacting with an environment that is rich in literacy. They learn to write by writing. Experiences with print which induce natural literacy development fall within every child's social contest. Literacy is, above all, a social process (Teale 1982). Teachers who wish their students to grow as writers must regard all pieces of writing as growing things to be nurtured rather than as objects to be repaired or fixed (Bissex 1981).

Many products of early writing appear to be more like cursive writing than print (Clay 1975, Ferreiro \& Teberosky 1982). Through their observations of and interactions with the people in their society, early writers are role-playing the experiences in which they eventually hope to participate. Writing just for the pleasure of writing initially motivates and satisfies young writers (Haley-James 1982). Ferreiro \& Teberosky's (1982) research concluded that children develop simple hypotheses about writing such as 1) it has shapes (circles), 2) shapes are separated (several circles), and 3) shapes go in lines (several circles in linear arrangement).

Somewhere between 3-5 years, most children become aware that people make marks on paper purposefully (Clay 1975). Children shift to new hypotheses as their current ones conflict with the written structures they encounter. Scribble writing and mock alphabet letters are signs that a child is beginning to know what writing does (Clay 1975). This experimen- 


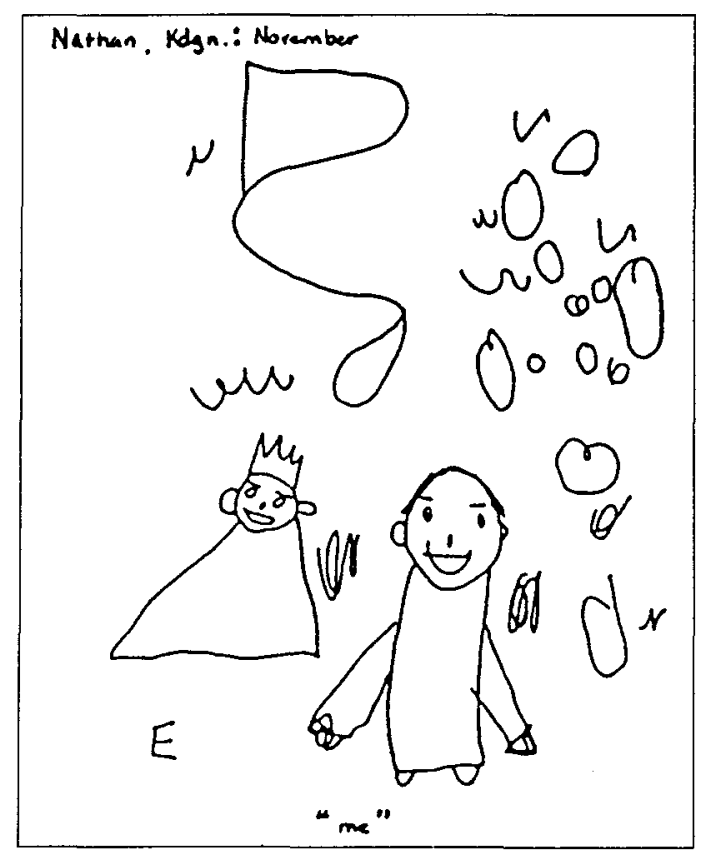

tation and hypothesis-testing of newly developed concepts are important in learning to express meaning through written words (Deford 1980).

Children are ready to write when they want to communicate through writing, and when they are interested in writing, and when they understand that written symbols represent meaning. Teachers must watch for children's signals that writing can begin and provide ample opportunities for early writers to show what they already know about written language's processes and functions. Understanding what children do allows teachers to make "connections" between teaching and learning to write (Dyson 1982).

In the late 60's, Henderson \& Beers (1980) began to apply a language acquisition model to children's writing. They reasoned that if they could find consistent patterns in children's misspellings, then they might infer from these the underlying concepts that guide children's writings. Henderson \& Beers (1980) found that children advanced in their knowledge of words through discernible conceptual stages and these stages hold great stability across different methods of instruction, mixtures of dialects, and even different languages. It is their contention that the teachers' understanding of what children know about words is the crucial factor for 
effective instruction in reading and writing. Children do, of course, learn letters and words directly from exposure to written language. However, what they can learn depends upon the conceptual frame they bring to the task. Successful teaching occurs when concrete guidance follows a solid understanding of the conceptual aspects of word knowledge, and when instruction is paced to the child's underlying conceptual grasp.

Read (1971) explored children's generalizations of phonological rules by examining their spontaneous writing. Through his investigations, he made hypotheses about how children perceive and organize the spoken forms they are representing. His research strongly suggested that young children catagorize speech sounds and invent their own spelling. Read (1975) noted that spontaneous spellers begin to spell words using blocks or other movable alphabet toys, and progress to production of written messages of all kinds. He further discovered that these young children can independently come to understand how written language works, and that the quality of adults' responses to spelling attempts was of paramount importance in encouraging invented spelling. When adults do not interfere with children's attempts to write by expecting them to correctly spell, punctuate, and capitalize letters from the outset, the children will arrive at roughly the same system of representation and follow the same general route to closer approximations to conventional English (Chomsky 1979, Henderson \& Beers 1980, Graves 1980, Bissex 1981). Like oral language acquisition, learning to write can also be viewed as a developmental learning task.

Gentry (1982) integrated his own observations with the research of Read (1971) and Henderson \& Beers (1980), and came up with a particularly useful model which delineates five major stages in spelling development of young children. He applied this developmental spelling classification system to the Bissex case study (Bissex 1980) to provide more recognizable stages as guidelines for teachers to assess and to foster writing development in children. The fact that these stages exist suggest "that learning to speli is not simple a matter of memorizing words but in large measure a consequence of developing cognitive strategies for dealing with English orthography" (Read \& Hodges 1982).

Early (1976) replicated Read's research using young subjects who were learning English as a Second Language (ESL). She discovered that L2 children (children learning a second language), like Ll children, can organize their perceptions of the phonetic features of English in a way which is consistent and systematic. Early's research is essentially a study of second language acquisition. It supports the notion that there is a high similarity between $\mathrm{Ll}$ and $\mathrm{L} 2$ children in their oral and written language development. 
A two-year project was set up to look at how ESL children learn to write. Its purposes were to: 1) investigate the processes and developmental stages in ESL children when acquiring a written language during the Kindergarten and Grade One years; 2) evaluate the resulting data of these L2 learners against the stages established for L1 learners; and 3) discover and evaluate the direct influences of specified oral language instruction on the writing behaviour of $\mathrm{L} 2$ learners. The ESL children were in a regular Grade One or Kindergarten class, and had begun writing within the first month of school. All the children received daily help in English language development from the English Language Centre (ELC). The ELC teachers provided instruction and assistance in both the oral and written language development of these children.

The children's writing samples serve to illustrate the stages of development which researchers have discovered in children's writing (Read 1975, Henderson \& Beers 1980, Gentry 1982). Dobson (1983) and Hurst et al (1983) established the five stages of writing development for firstlanguage learners. They used for their writing stages the same labels which Gentry had orginally established for his five stages in children's spelling development. Gentry identifies the first stage as the "Precommunicative Stage" (Gentry 1982). However, it has been well documented that children are communicating when "writing" (Bissex 1980, Goodman 1980, Ferreiro \& Teberosky 1982). It also had become evident in this project that most attempts in writing had meaning as its central focus. Therefore, the first stage of writing was more appropriately re-labelled as the PrePhonetic Stage of Writing (Chow 1986).

\section{The Pre-Phonetic Stage of Writing}

The primary feature of this stage is that the young writers do not operate with an understanding that letters have a correspondence to sound units of English. As a result, pre-phonetic writing is not readable.

As a pre-phonetic writer, Adrian used his knowledge of the alphabetic symbols to represent a message, even though there is not knowledge of letter-sound correspondence. He has a limited repertoire of letters, all upper-case, and includes number symbols as part of his writing. $\mathrm{He}$ appears to have established left-to-right directionality for English writing. Adrian is demonstrating his early hypotheses about how alphabetic symbols represent words. Within teacher-pupil interactions, meaning is stressed before form. Child "talk" is allowed and encouraged throughout the writing task. Graves (1980) reported that talk is paramount to the writing event, and that beginning writers show through voice alone that writing is much more of a speech event than a writing event. 
Adrian, Kdgn.: November

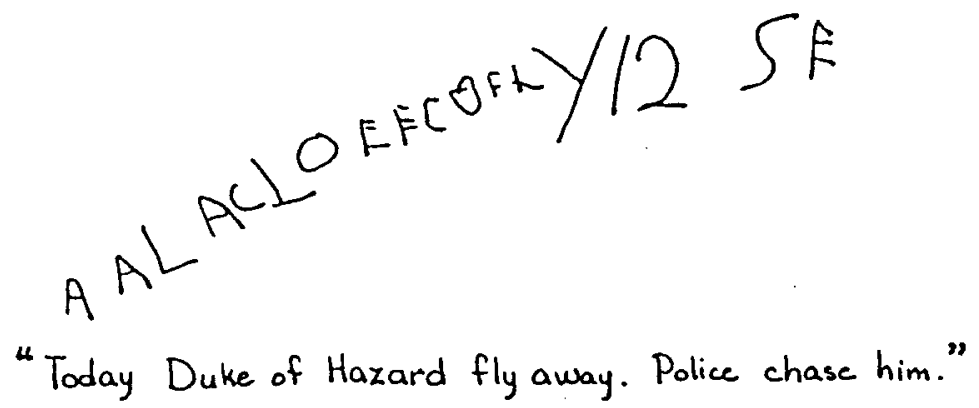

When children begin to use specific letters or letter combinations to represent sound units in their oral language, they are moving into the semi-phonetic stage. Movement from one stage to the next is not sudden and complete but flows and overlaps into it.

\section{The Semi-Phonetic Stage of Writing}

At this stage, children systematically use letters to represent words of parts of words to convey their message. This stage is characterized by the children's ability to partially map the letter-sound correspondences. They now use the conventional left-to-right orientation although some continue to reverse occasional letters.

Kevin, Gr. 1 : October

IMPDHK

$$
\text { I am playing the hackey. }
$$

Kevin; Gr.1: December

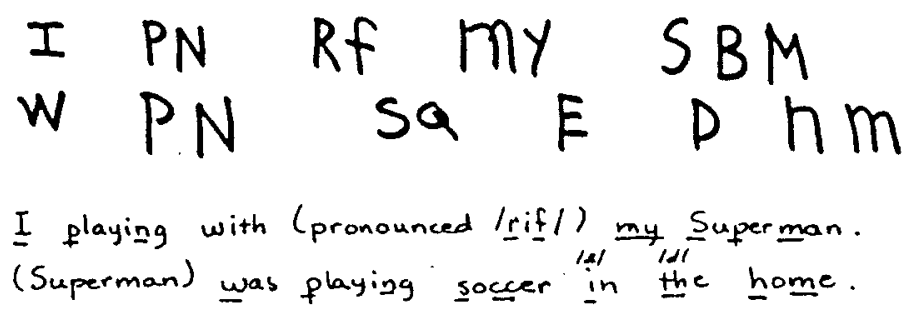


Kevin's work is characteristic of a semi-phonetic writer. Unlike writers in the first stage, he is representing letter-sound correspondence. It is in this second stage of writing development that a child first begins to conceptualize the alphabetic principle. Letters which are used to represent words provide a partial mapping of phonetic representation for the word being spelled (i.e. hk = hockey, $\mathrm{D}=$ the, pronounced "da"). Alphabet knowledge and mastery of letter formation become more complete, and word segmentation may or may not be in evidence.

Kevin arrived at school in the first week of October after four months holiday in Hong Kong. Previous to that, he had been in Canada for two months. Kevin had very little English with which to communicate. However, school was a social setting which induced language development because of a very basic human need to communicate and to interact with others (Goodman 1980). Children learn to talk by talking in an environment that is full of talk. Those children who learn to speak in a speech environment will learn to write in a literate environment (Bissex 1981).

\section{Nana, Kdgn.: January \\ IMOOL LEM \\ I am 5 . Me. (finger slid over extra letters before reading}

Nana is another semi-phonetic writer. Like Kevin, she used a letter name strategy which is very much in evidence at this stage (i.e. $M=a m$ ). Nana is also beginning to develop a visual strategy for word identification. Her new sight word (i.e. EM = me) is one that she is pleased to "show-off" and for which she receives much positive feedback. Her teacher does not correct this first attempt at a sight strategy. She fully expects to see "errors" in children's writing and is confident that Nana will discover the conventional spelling for herself. Nana's visual strategy is sophisticated for the semi-phonetic stage of writing. Nana's written communication reflects her existing understanding of written language. Her writing will gradually evolve through successive approximations toward the conventional form.

All the young writers in the project were expected to write on a daily basis and to come up with their own topics each day. However, Nana more than the other children in the project group incorporated the oral 
language work initiated by the teacher. At the time of this writing sample, oral language actitivites revolved around the theme, "All About Me".

When children represent many of the surface sound features of words, particularly vowels, they are moving into the phonetic stage.

\section{The Phonetic Stage of Writing}

At this stage, children can provide a total mapping of the letter-sound correspondence. All the surface sound features of the words being spelled are represented in the spelling.

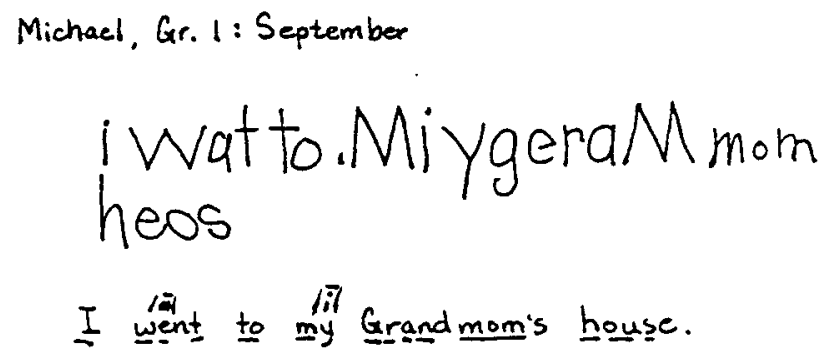

Michael provides an example showing characteristics of the phonetic stage. In this stage, the children show a far more complete understanding of letter-sound correspondences. All sound features in each word are represented according to the chld's hearing and articulation. While functional or invented spellings often do not conform to conventional English spelling, the choices are systematic and perceptually correct. Michael is able to provide a total mapping of letter-sound correspondence. Typically, Michael "sounds" words out slowly as he writes, thus distorting the word, house (i.e. "hi-ow-s" became heos). The letter name $e$ replaced the short vowel / $\mathrm{I} /$ which is commonly found in phonetic writing. This is due to the young writers' perception of the spelling based on the articulation points in the mouth. That is, the long (tense) vowel /iy/ is made in the same place in the mouth as the short (lax) vowel $/ \mathbf{I} /$. Similarly, the short vowel / $\varepsilon$ / is substituted with the long vowel / ey/ in "went". The nasal/n/ was dropped since it is difficult for writers at this stage of development to hear and to determine the activity inside the mouth when making the / $\mathbf{n}$ / sound in "went". Bissex (1980) reported that cognitive awareness of English orthography becomes markedly more developed in children who are allowed to invent their own spellings during their progression through the phonetic stage.

Michael's writing relates the experiences or events which are important to him. His writing seldom has the quality of a story. This is not uncom- 
mon in the first three stages of writing development. In this project, it became evident that even when a child responded to the teacher's oral language activity on a storybook or a song, he tended to make a reference to only one event, to introduce a new conclusion, or to repeat one familiar speech pattern.

Michael's piece of writing did not show word segmentation which is generally in evidence during the phonetic stage. Again, stages of development are not distinct but overlap into each other.

When children become more aware of the conventions of English spelling, they emerge into the fourth stage.

\section{The Transitional Stage of Writing}

During this stage, the writer undergoes a transition from reliance on phonology or sound for representing words in spelling to greater reliance on visual and morphophonemic representations which incorporate aspects of grammar and meaning. However, they continue to rely on a phonetic strategy for unfamiliar words, and so continue to feel free to express themselves fully.

In the project, none of the ESL children had reached the transitional stage of writing by the end of Grade One. However, this was not atypical within the total population of Grade One writers. Few first-graders were observed to have reached the transitional stage by the end of their first grade. This was further supported by observations over a four-year period. However, many children began to show signs of a new visual strategy which is characteristic of transitional writers. Movement from one stage of writing to another is not abrupt but gradual.

1. Michael, Gr. 1: January

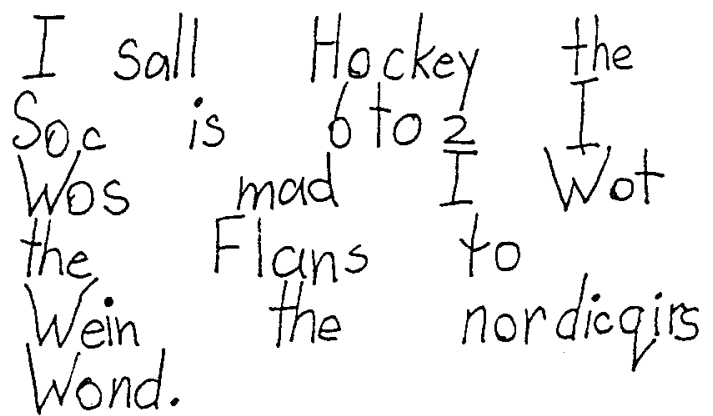

I saw hockey. The score is 6 to 2 . I was mad. I want the Flames to win.
The Nordiques won. 
2. My Lint, Gr. 1: December

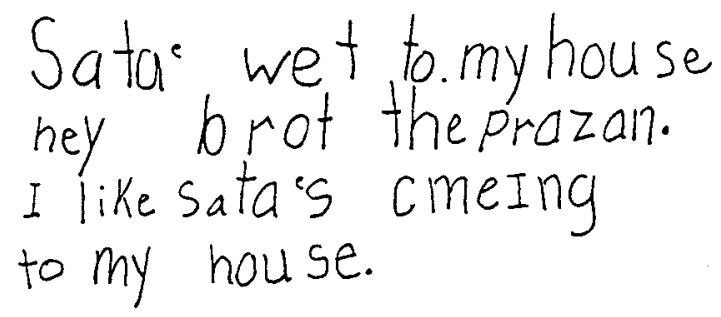

Santa went to my house. He brought the present. I like Santa's coming to my house.

Michael and My Linh show signs of transitional writing when they include familiar spelling patterns, although inappropriately, in their writing (i.e. sall $=$ saw, hey $=$ he). Interestingly, both children still occasionally drop their nasal $/ \mathrm{n} /$ before a consonant - a feature more prevalent in an earlier stage (i.e. wot/want, wet/went). Again, movement between stages is normal and is to be expected. Invented or functional spellings are interspersed with correctly spelled sight words. Suffixes such as the "-ing" are being used successfully although experimentation with the written language continues. Transitional writers show evidence of a new visual strategy; the child moves from phonological to morphological and visual spelling.

Both writers chose to write about events which were meaningful to them. Britton (1970) described the expressive forms of writing as the earliest forms because they arise out of the writers' experience and take less account of audience. Michael, however, has shown a developing sense of audience between his two writing samples. The "hockey" story gives more detail to the reader; it is complete. Michael does not assume a shared context with the reader to the same degree as he did in his earlier piece. With increasing exposure to and amount of experience with different literary forms, developing writers gain a sense of the conventions of stories. A growing sense of audience also prompts young writers to use punctuation (Graves 1980). My Linh had been experimenting with question marks, exclamation marks, apostrophes, and periods for several weeks. Her attempts, however unconventional, were met with respect and encouragement. The fact that she is beginning to use punctuation correctly more often indicates her growing understanding of the conventions of print and her growth as a writer.

At this stage of development, writers are more prepared to incorporate teacher-initiated oral language work into their writing. In this project, 
formal language lessons focussed heavily on story books, nursery rhymes and poems to stimulate oral language development. The criteria for the choice of literary material was on 1) their use of children's natural language, 2) their use of repetition and patterns to increase predictability of language, and 3) their use of recognized story conventions. The children were invited to predict words or phrases and to join in on second or third readings. They were encouraged to participate in the re-tells of familiar stories. The teacher expected all children to participate orally in all activities while accepting that each child will do so at his own language level. This expectation also applied to written activities.

Now that spelling is more automatic, the children write much more. They move from real events to imaginary ones. Their stories begin to show a beginning, middle and end. They retell favourite stories or recreate new ones using familiar storylines. They are looking for new audiences. Reading to the class becomes popular. This is the start of publishing for a wider audience in which the need to write according to the conventions becomes purposeful.

When children begin to incorporate many visual and morphophonemic aspects in their writing, they demonstrate that they are moving into the Conventional Stage of Writing Development. Gentry (1982) referred to this stage as the "Correct Stage". At this stage of development, the speller's knowledge of English orthography is set. Similarly, young writers in the conventional stage of writing have worked out the basic rules of the English orthographic system, and now are free to focus more on the composition and organization of ideas (Chow 1985).

Observations in the classrooms fully support the findings of early writing research. Children can - and do-learn to write independently within an interactive and supportive environment rich in language. In our project, ESL children demonstrate that they use the strategies and follow the same general patterns of development in their acquisition of written language as their L1 counterparts. Written language development can parallel oral language development in children who are learning a second language. The processes involved in learning an oral and written language are very similar; development in one area supports and reinforces learning in the other. DeStephano (1978) argued that oral language, reading and writing are "outputs from a cognitively managed set of communicative competencies" and that one enriches the other through the many experiences in all.

Literacy develops in all children in a highly literate society. Young children learn to write because they are engaged in the process of language development. At every grade level, there is a need to communicate and to record thoughts. There is a message in any attempt to write. Children 
learn to write because they want to write. Teachers must recognize and respond to this need. Writing, therefore, should be an integral part of early literacy programs - both in regular classrooms and ESL classes. A supportive, accepting environment in which children feel free to experiment and to risk errors allows for maximum exploration of the processes of literacy.

\section{REFERENCES}

Bissex, G. (1981). Growing writers in classrooms, Language Arts, 58(7), 785-791. Bissex, G. (1980). GNYS AT WRK: A child learns to write and read. Cambridge, Mass: Harvard University Press.

Britton, J. (1970). Language and learning. London: Allen Lane Penguin.

Brown, R. (1973). A first language: The early stages. Cambridge, Mass.: Harvard University Press.

Chow, M. (1986). The acquisition of written language by children who are learning English as a second language. Vancouver, B.C.: Educational Research Institute of British Columbia.

Chow M. (1985). Conferencing emergent writers. Ideas. Vancouver, B.C.: Vancouver School Board.

Chomsky, C. (1979). Approaching reading through invented spelling. In L.B. Resnick and P.A. Weaver (Eds.), Theory and practise of early reading (Vol. 2). Hillsdale, N.J.: Lawrence Eribaum Associates.

Clay M. (1975). What did I write? Toronto, Ont.: Heinemann Educational Books.

Deford, D. (1980). Young children and their writing. Theory into practice, 19, 157-162.

DeStephano, J.S. (1978). Language, the learner and the school. New York, N.Y.: Wiley \& Sons, Ltd.

Dobson, L. (1983). The progress of early writers as they discover written language for themselves. Vancouver, B.C.: Educational Research Institute of British Columbia. (ERIC Document Reproduction Service No. ED 235 505).

Early, M. (1976). The categorization of the speech sounds of English by nonnative children. Unpublished master's thesis. Language Education Resources Centre, University of British Columbia, Vancouver, B.C.

Ferriero, E. and Teberosky, A. (1982). Literacy before schooling. Trans. by K. Goodman Castro. Exeter, N.H.: Heinemann Educational Books.

Gentry, J. (1982). An analysis of developmental spelling in GYNS AT WRK. The reading teacher, 36(2), 192-200.

Goodman, Y. (1980). The roots of literacy. Claremont Reading Conference, 44, $1-32$.

Graves, D. (1981). Patterns of child control of the writing process. In R.D. Walshe (ed.), Donald Graves in Australia "Children want to write...". Exeter, N.H.: Heinemann Educational Books.

Graves, D. (1980). Children's writings: Research directions and hypotheses based upon an examination of the writing processes of seven-year-old children. Ann Arbor, Michigan: University Microfilms International. 
Haley-James, S. (1982). When are children ready to write? Language Arts, 59(5), 458-463.

Henderson, E.H. and Beers, J.W. (Eds.) (1980). Developmental and cognitive aspects of learning to spell: $A$ reflection of word knowledge. Newark, Del.: International Reading Association.

Hurst, M., Dobson, L., Chow, M., Nucich, J., Stickley, L. and Smith, G. (1983). A program to foster literacy: Early steps in learning to write. Vancouver, B.C.: B.C.T.F. Lesson Aids.

Menyuk, P. (1971). The acquisition and development of language. Englewood Cliffs, N.J.: Prentice-Hall.

Read, C. (1975). Children's categorization of speech sounds in English, Research Report No. 14. Urbana, Ill.: National Council of Teachers of English.

Read, C. (1971). Pre-school children's knowledge of English phonology. Harvard Educational Review, 41(1), 1-34.

Read, C. and Hodges, R. (1982). Spelling. Encyclopedia of Educational Research, 5th ed. New York, N.Y.: Macmillan.

Teale, W. (1982). Toward a theory of how children learn to read and write naturally. Language Arts, 59(6), 555-570.

\section{THE AUTHOR}

Mayling Chow is an elementary school ESL teacher in Vancouver. She also teaches emergent writing to classes of regular non-ESL students. She is the recipient of an ERICBC grant to look at the acquisition of written language by ESL students. She has also co-authored a program to foster literacy: Early Steps in Learning to Write, which is a British Columbia Teacher's Federation Lesson Aid. 